\title{
Chica bytes: Uma oficina de Introdução a Computação no Curso de Bacharelado Interdisciplinar de Ciência, Tecnologia e Inovação.
}

\author{
Lucas Almeida Silva ${ }^{1}$, Queilane da Conceição Rocha ${ }^{1}$, Amanda Vilas Boas Oliveira ${ }^{1}$, \\ Yasmin Solrac Ribeiro dos Santos ${ }^{1}$, Felipe de Melo Santos ${ }^{1}$, Guilherme Gonçalves da Silva ${ }^{1}$, \\ Érica Pereira Machado ${ }^{1}$
}

${ }^{1}$ Instituto de Ciência, Tecnologia e Inovação - Universidade Federal da Bahia (UFBA)

Rua do Telégrafo, s/n, Centro - Camaçari - BA. Cep: 42809-000

lucas.almeida.las@ufba.br, \{queilane.rocha01, aymevbo, yasminsolrac66,

fmello3109,ggoguilherme194, erica.tecnicoit\}@gmail.com

\begin{abstract}
This article presents an experience report from an Introduction to Computing workshop for intrant of an Interdisciplinary Bachelor's Degree in Science, Technology and Innovation, aiming to smooth the first contacts with the Computing and to problematize the role of women in science and technology. The workshop consists of 3 meetings with 4 hours each, totaling 12 hours of workload.
\end{abstract}

Resumo. Este artigo apresenta um relato de experiência de uma oficina de Introdução a Computação para calouras do curso de Bacharelado Interdisciplinar de Ciência, Tecnologia e Inovação, objetivando suavizar os primeiros contatos com a área e problematizar o papel da Mulher em Ciência e Tecnologia. A oficina teve 3 encontros de 4 horas cada, totalizando 12 horas.

\section{Introdução}

Apesar das mulheres serem maioria no Ensino Superior, isso não se reflete nas carreiras e cursos das áreas de Computação e afins [Grossi et al. 2016]. As mulheres representam uma parcela pequena da comunidade de Computação [Cohoon and Aspray 2006]. Além disso, a quantidade de mulheres que ingressam nos cursos de Computação tem reduzido cada vez mais, sendo a atratividade um desafio de diversos projetos [Santos 2018]. O Bacharelado Interdisciplinar (BI) é uma proposta relativamente nova de educação superior e conta com três ciclos de educação: 1) O BI, 2) Formação profissional e 3) Pós-Graduação. O BI é caracterizado, principalmente, por sua flexibilidade de organização curricular e maior autonomia do estudante na escolha de seu perfil profissional. [Camargo et al. 2010]. Tendo em vista, a Chica Bytes iniciou suas atividades em abril de 2019, na cidade de Camaçari, com ações voltadas a promover a área de Computação entre mulheres dos diversos públicos. Além disso, desenvolveu uma oficina para calouras do curso de Bacharelado Interdisciplinar em Ciência, Tecnologia e Inovação (BI-CTI), objetivando discutir e desconstruir esteriótipos dos perfis das áreas de Ciência, Tecnologia e Engenharia (CT\&E). Este artigo apresenta o relato de experiência dessa oficina, o seu planejamento e lições aprendidas. Na Seção 2 constam os trabalhos Correlatos; a Seção 3 apresenta as Ferramentas e Materiais e o Planejamento, Participantes e Organização; a Seção 4 descreve a Nossa Experiência em cada encontro; a Seção 5 apresenta as nossas lições aprendidas e a Seção 6 apresenta as Conclusões desse trabalho. 


\section{Trabalhos Correlatos}

O programa Techno Girls (UFMT), 2018, realizou oficina de programação de jogos para estudantes de escolas públicas da cidade de Rondonópolis(MT), destacou-se a importância de temas que apresentem o papel das mulheres na Computação, principalmente, para estudantes do sexo masculino, visto que as reflexões coletivas podem colaborar na valorização do papel feminino nas ciências [Júnior et al. 2019]. No projeto Meninas Digitais no Cerrado foi destacado a violência de gênero através dos esteriótipos sexistas vigentes na área de Computação e os seus possíveis impactos na autoestima e no desempenho das estudantes. O projeto utilizou de uma ideia de contra-discurso para desnaturalizar os estereótipos normalizados [Louzada et al. 2019]. Já no projeto Elas.net (CEFETMG), desenvolveu-se três ações para integração entre professoras e alunas, sendo elas: (i) encontros de bate papo, (ii) palestras sobre o Mercado de Tecnologia da Informação (TI) e (iii) roda de conversa sobre a questão de gênero[Ferreira et al. 2019]. No trabalho da (UEA-AM) foi proposto uma mentoria com estudantes do curso de Computação, objetivando avaliar os fatores que culminam na reprovação de mulheres na disciplina de Introdução a Programação e se esse fatores poderiam ser minimizados com a participação em Grupo de Estudos[Franzoia et al. 2019]. Esses trabalhos apresentam estratégias de ambientes de diálogo, debate e conscientização sobre mulheres em Computação. Contudo, essas abordagens são comuns em cursos de progressão linear em Computação e afins, não abordando o tema sob a ótica dos cursos de BI em Ciência e Tecnologia (C\&T).

\section{Organização da Oficina}

\subsection{Ferramentas e Materiais}

Scratch é um ambiente de programação visual desenvolvido pelo MIT Media Lab, objetivando tornar a programação de computadores fácil de aprender para qualquer pessoa, independente da idade, nível de escolaridade, interesse e conhecimento em programação de computadores. Para que essas pessoas construam suas próprias animações, jogos, simulações, além de compartilharem seus projetos em uma plataforma on-line [Resnick et al. 2009]. Arduino é uma plataforma eletrônica de código aberto baseada na facilidade do uso do hardware e software. As placas Arduino objetivavam reduzir os entraves no desenvolvimento de hardware por parte de estudantes universitários em cursos das áreas de Computação [Arduino 2020]. Além desses, um material didático foi desenvolvido pela equipe do projeto, sendo três caixas no seguinte formato: (i) 1 ou 2 botões chave de pressão na parte frontal da caixa e (ii) uma lâmpada na parte superior da caixa. Cada caixa representava um operador lógico. Além desses, foram utilizados também: protoboard, botões, leds, baterias, resistores e os CIs família TTL da série 7400.

\subsection{Planejamento, Participantes e Organização}

A oficina foi planejada com carga horária de 12 horas, distribuídas em 3 encontros de 4 horas. Em cada encontro, tínhamos dois membros do projeto como tutores das atividades, sendo os demais participantes monitores. Esta oficina é uma primeira incursão e possui dois principais objetivos: (i) discutir a questão do gênero nas áreas de Ciência e Tecnologia (C\&T) e (ii) suavizar o impacto do primeiro contato com assuntos da área de Computação como: Eletrônica, Circuitos Digitais e Programação. A Tabela 1 apresenta uma visão do planejamento da oficina por encontro. Os participantes da oficina são estudantes recém-ingressos no semestre 2020.1 e foram convidadas no primeiro dia de aula, 
sendo a participação facultativa. A oficina foi mediada por 6 estudantes do BI-CTI e um orientador técnico, contando com a participação de 18 participantes, sendo $11(61,11 \%)$ do sexo masculino e $7(38,89 \%)$ do sexo feminino.

Tabela 1. Planejamento dos encontros da Oficina

\begin{tabular}{|c|l|l|l|}
\hline Dia & Conteúdo & Atividades & Objetivos \\
\hline \multirow{2}{*}{01} & $\begin{array}{l}\text {-Papel da Mulher na Ciência, } \\
\text { Tecnologia e Inovação; } \\
\text {-Sistemas de Numeração: } \\
\text {-Portas Lógicas: (e, ou, não); } \\
\text {-Tabela Verdade }\end{array}$ & $\begin{array}{l}\text {-Dinâmica de grupos } \\
\text {-Enviando mensagens } \\
\text { secretas } \\
\text {-Dinâmica: a cabra cega }\end{array}$ & $\begin{array}{l}\text {-Construir sororidade } \\
\text { entre as estudantes; } \\
\text {-Conversão entre sistemas } \\
\text { numéricos; } \\
\text {-Portas lógicas e } \\
\text { suas tabelas verdade; }\end{array}$ \\
\hline \multirow{2}{*}{02} & $\begin{array}{l}\text {-Leitura de Esquemático; } \\
\text {-Montagem de Circuito em } \\
\text { Protoboard; } \\
\text {-Cálculo de resistor } \\
\text { do led e pull down }\end{array}$ & $\begin{array}{l}\text {-Montagem de circuitos: } \\
\text {-Acende led com/sem } \\
\text { botão; } \\
\text {-Acender led como } \\
\text { resultado de porta lógica; }\end{array}$ & $\begin{array}{l}\text {-Identificar componentes } \\
\text { pela simbologia; } \\
\text {-Entender a montagem em } \\
\text { Protoboard; } \\
\text {-Calcular resistor para } \\
\text { o led e entrada de CI; }\end{array}$ \\
\hline \multirow{2}{*}{03} & $\begin{array}{l}\text { - Mulher na Sociedade; } \\
\text {-Controle de Movimentação; } \\
\text {-Sensores; } \\
\text {-Condicionais e objetos }\end{array}$ & $\begin{array}{l}\text {-Debate do contexto: } \\
\text { "Só por ser quem eu sou”; } \\
\text {-Dinâmica da troca da } \\
\text { lâmpada }\end{array}$ & $\begin{array}{l}\text { no Scratch; } \\
\text {-Utilizar condições de forma } \\
\text { adequada; } \\
\text {-Relacionar portas lógicas } \\
\text { aos operações lógicos. }\end{array}$ \\
\hline
\end{tabular}

\section{Nossa Experiência}

\subsection{Encontro 1 - Papel das Mulheres na Ciência, Tecnologia; Introdução a Sistemas Numéricos e Portas Lógicas}

No início da oficina, dividimos os calouros em dois grupos: meninas e meninos. Os grupos foram colocados em salas diferentes. Introduzimos a proposta do projeto Chica bytes e o objetivo da oficina para ambos os grupos. Durante uma hora fizemos um debate sobre o papel da mulher nas áreas de C\&T, os esteriótipos sexistas, as experiências e os efeitos de uma masculinidade tóxica na construção da suas identidades adultas. Depois disso, foram divididos em quatro grupos sendo uma garota a líder. Logo após, foi feita uma breve introdução aos sistemas de numeração, seguida por uma dinâmica da contagem de pontos e do envio de mensagens secretas de computação desplugada [Bell et al. 2012]. Em seguida, utilizando as caixas das portas lógicas realizamos a dinâmica da cabra cega. No fim, foi apresentado os conceitos de portas lógicas, tabela verdade e as operações da álgera relacional. Um desafio para o próximo encontro foi entregue as equipes.

\subsection{Encontro 2 - Leitura e Implementação de Esquemáticos de Projetos Simples em Protoboard}

O segundo encontro foi realizado dois dias após o primeiro. Nesse encontro, realizamos as atividades no Laboratório de Informática. As equipes apresentaram os resultados obtidos no desafio do primeiro encontro. Apenas as líderes podiam realizar as apresentações, 
pois queríamos aumentar a participação das meninas em apresentações. Fizemos revisões de conceitos como: corrente, tensão, resistência e lei de Ohm. Em seguida, introduzimos o funcionamento da protoboard e de alguns componentes eletrônicos e suas simbologias. Um circuito em série simples foi montado junto com as equipes. Após isso, as líderes foram desafiadas a montar um circuito que acendia o led apenas quando o botão pressionado. Todas as equipes conseguiram realizar a atividade. Por último, montou-se um circuito com dois botões e um CI de porta lógica (NÃO), onde foi ensinado o cálculo para o resistor de pull down e os efeitos da ausência desse tipo de resistor no comportamento dos CIs. A montagem foi realizada com um pouco de dificuldade, mas não demonstraram dificuldades no cálculo do valor do resistor de pull down. As equipes foram desafiadas a montar o circuito do desafio da porta XOR, mas devido ao horário, essa implementação foi postergada.

\subsection{Encontro 3 - Continuação do Debate sobre Mulheres na Ciência e Sociedade, Introdução a programação com Scratch e Arduino}

O último encontro foi realizado cinco dias depois do segundo. O intervalo de tempo foi maior por conta de outras atividades no instituto no mesmo período. Retomamos, nesse último dia, ao debate sobre Mulheres na Sociedade com a dinâmica: "Só por ser quem eu sou ...”. Nessa dinâmica, algumas frases como: "Só por ser quem eu sou, eu sou interrompida, muitas vezes, por outros colegas quando estou falando", "Só por ser quem eu sou, eu tenho que obrigatoriamente mostrar que sou melhor que os outros para me darem valor e atenção", foram utilizadas para discutirmos os privilégios dos homens dentro da sociedade e mercado de trabalho. Essa discussão trouxe uma série de experiências tanto das garotas quanto dos garotos. Entretanto, extrapolamos o tempo planejado, mas mantivemos a discussão por acreditarmos que essa experiência era enriquecedora. Finalizado o debate, iniciou-se a etapa da oficina com programação com Scratch e Arduino. As equipes foram desafiadas a descrever o passo a passo das ações de um robô trocando uma lâmpada. O detalhamento dessas ações foram transportadas para o Scratch, trabalhando com os blocos de controle, sensores e movimento. A tutora falou brevemente da placa arduino, pois o tempo previsto já tinha ultrapassado.

\section{Lições Aprendidas}

Algumas das lições aprendidas podem ser listadas como se segue: (i) O debate com grupos separados por sexo promoveu uma maior abertura para o diálogo e exposição; (ii) as atividades desplugadas são ferramentas úteis para esses conceitos introdutórios; (iii) as apresentações de resultados aumentam a confiança das líderes das equipes, que ao passar dos encontros estavam mais confiantes de sua postura e modo de apresentar; (iv) a carga horária e o número de encontros não foram suficiente para a execução do planejamento proposto, sendo necessário uma ampliação desses; (v) retornar o debate sobre as Mulheres nos diversos espaços foi frutífero e deve ser realizado mais vezes durante as oficinas; (vi) não se tratou apenas de uma oficina de Introdução a Computação, mas de compreender os dilemas que mulheres vivem, assim como construir uma relação de sororidade entre as garotas do BI-CTI, afim de colaborar na permanência dessas no curso.

\section{Conclusões}

Apesar da oficina ser direcinada a valorizar a presença da mulher em cursos das áreas de CT\&E e auxiliar no desenvolvimento de um sentimento e uma relação de sororidade entre 
as estudantes do BI-CTI, levar as reflexões oriundas dos coletivos de mulheres das mais diversas áreas para os estudantes do sexo masculino pode contribuir para que esses rapazes aprendam a valorizar o papel das mulheres nas ciências, além de reduzir esteriótipos naturalizados de competência e habilidades. A utilização de momentos distintos auxiliou para a construção de um espaço de fala mais confortávle para as estudantes ao longo da oficina. O principal impacto desse trabalho não se dá pela atração, mas a perspectiva de retenção dessas estudantes no BI, visualizando a área de Computação como possível ramo profissionalizante de sua formação. Em trabalhos futuros, desejamos criar um evento de um dia voltado apenas para as estudantes do BI-CTI, contando com cursos para capacitação e aprimoramento técnico, além de mesas redondas, palestras, dentre outras ações.

\section{Referências}

Arduino (2020). What is arduino? Disponível em: https://www.arduino.cc/en/guide/introduction.

Bell, T., Rosamond, F., and Casey, N. (2012). Computer Science Unplugged and Related Projects in Math and Computer Science Popularization, pages 398-456. Springer Berlin Heidelberg, Berlin, Heidelberg.

Camargo, M. S., Rehem, C. M., Rauh, Y. M., dos Santos Rosa, D., Leal, M. C., Magrone, E., and de Almeida Filho, N. (2010). Referenciais orientadores para os bacharelados interdisciplinares e similares.

Cohoon, J. M. and Aspray, W., editors (2006). Women and Information Technology: Research on Underrepresentation, volume 1. The MIT Press, 1 edition.

Ferreira, K., Barbosa, G., and Albuquerque, S. (2019). Uma iniciativa para apoiar e empoderar alunas de ensino técnico e de graduação em computação. In Anais do XIII Women in Information Technology, pages 104-108, Porto Alegre, RS, Brasil. SBC.

Franzoia, F., Pires, F., and Pessoa, M. (2019). Mentorando meninas iniciantes em programação: um estudo de caso. In Anais do XIII Women in Information Technology, pages 199-203, Porto Alegre, RS, Brasil. SBC.

Grossi, M., Borja, S., Lopes, A., and Andalécio, A. (2016). As mulheres praticando ciência no brasil. Revista Estudos Feministas, 24(1):11-30.

Júnior, W., Santos, L., Manzano, A., Ângela Farias, Souza, T., Badji, I., Prietch, S., and Resmini, R. (2019). Techno girls: oficinas de programação de jogos para estudantes de escolas públicas. In Anais do XIII Women in Information Technology, pages 11-20, Porto Alegre, RS, Brasil. SBC.

Louzada, N., Santana, T., Assis, I., Braga, R., and Braga, A. (2019). Agindo sobre a diferença: atividades de empoderamento feminino em prol da permanência de mulheres em cursos de tecnologia da informação. In Anais do XIII Women in Information Technology, pages 69-78, Porto Alegre, RS, Brasil. SBC.

Resnick, M., Maloney, J., Monroy-Hernández, A., Rusk, N., Eastmond, E., Brennan, K., Millner, A., Rosenbaum, E., Silver, J., Silverman, B., and Kafai, Y. (2009). Scratch: Programming for all. Commun. ACM, 52:60-67.

Santos, C. M. (2018). Por que as mulheres “desapareceram” dos cursos de computação? 